\title{
Partial Pressure of Oxygen Adjusted for Body Temperature Measurement
}

National Cancer Institute

\section{Source}

National Cancer Institute. Partial Pressure of Oxygen Adjusted for Body Temperature Measurement. NCI Thesaurus. Code C147417.

The determination of the partial pressure of oxygen, adjusted for body temperature, present in a sample. 